\title{
The Cognitive Bases of Conversion in Modern English
}

\author{
Laila Sahib Gadimova \\ Azerbaijan University of Languages, Azerbaijan
}

\begin{abstract}
As known, the end of the 20th - the beginning of the 21st centuries in linguistics is characterized by language learning and studying the language processes from the perspective of anthropocentric paradigm. Moreover, at the age of globalization and innovative technologies, it was the English language that became the working language throughout the world which could not but affect its system. With spread of internet in virtual communication people tend to use the tools to save language. Despite the fact that in the scientific literature there is a great deal of works devoted to the study of different aspects of conversion, there is not a single study in which conversion would be considered as a mechanism of the principle of language saving. The relevance of our study is also explained by the fact that, unlike our predecessors, we consider conversion not as a word-building tool or one of the types of transposition, but as a universal language tool that needs a more detailed and complete description in the language. It is conditioned with the need to consider the factors of cognitive nature that determine the appearance and choice of particular conversion, both as reflection of the needs of the language itself and the communicative tasks of the speaker.
\end{abstract}

Index Terms - conversion, word formation, metaphorical, homonyms, transfer

\section{INTRODUCTION}

The problem of studying conversion is not new in the English language. The history of the study of the current issue includes an extensive literature examining this problem from different aspects- empirical, syntactical, structuralistic. The consideration of cognitive aspect of conversion in the English language was conducted within the framework of elaborating the cognitive theory of metaphor proposed by G. Lakoff and M. Johnson. Later, this position was reflected by works of R. Mendoza, O. Velasko, I. Balteyro, S. Martsa, etc. The study of conversion in Russian linguistics is contained in the classical works by E. S. Kubryakova, V. A. Gureeva, E. M. Pozdnakova, O. G. Ilyinskaya, etc. In Russian linguistics, conversion was considered as a structural means of word formation of the English language in works by M. Mammadov, H. Gadjiyev, S. Orudjev, R. Guseynov, Q. Babanli, R. Nasirov, etc.

The main goal of our research is to study the cognitive basis of conversion in modern English language.

To achieve the main goal, the following tasks have been put:

- to trace the history of study of conversion in the English language presented in foreign and Azerbaijani linguistics;

- to determine the aspects of studying conversion in modern English language;

- to consider conversion as one of the mechanisms of the language saving principle;

- to study conversion at the different levels of the language;

- to highlight the kinds and types of conversion;

- to reveal the structural models of conversion;

- to define the semantic component of conversion;

- to identify the types of semantic transfers on the basis of which the conversion is based;

- to identify the distinctive features of conversion as a semantic phenomenon of the language;

- to determine the effect of conversion on the development in terms of the language phenomena of polysemy, homonymy, synonymy, antonymy;

- to determine the cognitive nature of conversion;

- to reveal the connection between the effect of conversion and the development of language categories;

- to set the cognitive-communicative goal of conversion;

- to determine the effect of conversion in actualization of the various concepts;

- to identify the role of conversion in verbalization of the various concepts.

\section{RESEARCH METHODS}

Based on the tasks set during the analysis, the research used complementary methods, including the methods of semantic interpretation, cognitive and contextual analysis. In particular, the following methods have been also used: synchronous method, descriptive method, observation method, method of linguistic analysis.

Scientific novelty of the research lies in the fact that for the first time in linguistics, conversion has been examined as a mechanism of the principle of language saving. As a result of such approach, the structural models and the semantic component of conversion have been defined. The classification of its structural models is carried out and the 
semantic transfer is discovered, based on which the conversion is built. Also, the cognitive principle of the conversion is discovered, which influences on the units at the different levels of the language.

Theoretical significance of the research is determined by the fact that the study of conversion from the cognitive point of view has fostered defining conversion as a universal phenomenon of the language, structuring the language units in a systematic order.

Practical significance of the research is determined by the fact that the materials examined in the research can be used at the classes on general linguistics, at the special courses on cognitive linguistics, as well as disciplines related to the study of theory and practice of the English language at the faculties of philology.

\section{DISCUSSION}

The problem of studying conversion is not new in the English language. The history of the study of the current issue includes extensive literature. Considering this fact and modern achievements of linguistic science, all scientific research related to the features of the functioning of the conversion can be classified into two groups: 1) study of conversion from the point of view of traditional grammar; 2) studies of the cognitive characteristics of the functioning of conversion (Smirnitsky 1954, p.54).

The following stages of determining this grammatical phenomenon are distinguished in the history of the study of conversion.

1) Conversion refers to the transition of one part of speech to another (the end of the 17th and the beginning of the 18th centuries). During the compilation of English grammars, researchers such as Lane, Greenwood, Ward, Hazel, etc. focused not on the structural, but on the conceptual description of the conversion.

2) Conversion means the use of the same word in the functions of different parts of speech, or the functional transition from one part of speech to another (the end of the 19 century). This understanding of conversion is associated with the development of syntax theory in English grammar: words related to the different parts of speech are not considered in isolation, but within the framework of the sentence structure. This provision of polyfunctionalism is reflected in the works of Morris, Sweet, Crazing, Bradley.

3) Conversion as a way of word formation using zero morphemes (the end of the 19th and the mid of the 20th centuries): structuralistic approach.

One of the first researchers who considered conversion as a word-building phenomenon was L. Bloomfield, who spoke about the formation of zero words with the help of the zero element, and called the conversational units "secondary conversed words." L. Bloomfield's ideas about conversion as a zero derivation in the second half of the 20th century were developed (Bloomfield 1933, p.64).

The presence of zero affix in the word during conversion was also noted by Russian linguists, who began to pay close attention to English word formation from the 60-80s of the 20th century. Classic works in this direction are the works of E. S. Kubryakova, O. D. Meshkov, P. V. Tsarev, P. M. Karashuk, etc. in which conversion was considered as a morphological-syntactic type of word formation.

In Azerbaijani linguistics, conversion in the English language as an object of research has attracted the attention of scientists over the last 20 years. Here refer "About conversion" by Mammadov M. (Mammadov 2006, p.87 ), "The role and importance of neologisms in the development of conversion phenomena and techniques in linguistics" by Gadjiyev H. (Hadjiyeva 2015, p.109), “The phenomenon of conversion in language” by Orudjev S. (Orudjeva 2016, p.5), "New words creation in English by means of conversion and the methods of its expression in Azerbaijani" by Huseynova R. (Huseynova 2017, p.80), "Semantic analysis of the term "conversion” by Babanli Q. (Babanl 12017, p.11), "Typology of morphological methods in multi-system languages" by Nasirova R. (Nasirova 2017, p.13), etc. As can be seen from the titles of these studies, the conversion is considered by them as a structural means of word formation in the English language both in the comparative historical and comparative typology aspects.

Summarizing what is mentioned above, it becomes clear that conversion was considered both as semantic and grammatical (taking into consideration either syntactic or morphological features) means of word formation. From the mid of the 20th century, with the emerging of cognitive linguistics, the nature of conversion has been studied from a cognitive point of view.

In English linguistics, the consideration of conversion in the cognitive aspect was part of the development of the cognitive theory of metaphor and metonymy, proposed by G. Lakoff and M. Johnson (Lakoff 1988, p.102; Lakoff, Johnson 2002, p.111).

In Russian linguistics, conversion in the cognitive aspect was studied in the framework of the theory of conceptual analysis proposed by E.S. Kubryakova in the 70th of the 20th century (Kubryakova 1991, p.4-11). Further, this linguistic phenomenon was considered by E. M. Pozdnyakova, O.G. Ilyinskaya and others.

With regard to the cognitive approach to the study of conversion in Azerbaijan, despite the active development of cognitive linguistics by such scientists as F. Veysalli, A. Mammadov, M. Mammadov, there are no works devoted to this issue. Our work in Azerbaijan is the first work in which the conversion in English is considered from the point of view of cognitive linguistics.

One of the principles of the organization and existence of the language is the principle of saving the language, when the language seeks to achieve the greatest result using less means. 
S. O. Kartsevsky believed that this phenomenon is possible due to the asymmetric dualism of the sign, when the external sign (its shape) and the internal sign (its meaning) are manifested in the fact that the form of the sign is constantly transferred to other things, and one form starts to have several meanings: the new is included in the old frames (Kaptsevskiy 1965, p.85).

This is observed due to the fact that there are a limited number of signs in the sign system, while there are an infinite number of individual objects, phenomena, qualities, signs, properties, that is, all the expression of which can be found in the language. As a result, the same signs, by analogy, begin to name different concepts. Conversion in this case is a mechanism that includes the new in the old framework and changes the internal content of the sign qualitatively. This can be seen on the example of the sign /a/ of the modern English language, which manifests itself differently at the different language levels. So, at the phonetic level, the sign /a/ in written form is denoted by the letter /a/, the acoustic image of which is transmitted by different sounds.

Under stress in an open syllable /a/ sounds like [ei] (take, place, make), in a closed syllable - like [æ] (glad, bad, map).

In combination with other signs, it may indicate other sounds:

[a:] (park, car, mark) (park, işarə)

$\mathrm{a}+\mathrm{r}[\varepsilon ə]$ (care, pare) (qayğı, cüt)

[ə] (similar)

$\mathrm{a}+\mathrm{y}$ day, may, way

[ei]

$\mathrm{a}+\mathrm{i}$ (rain, pain) (yağış, ağrı)

$\mathrm{a}+\mathrm{i}+\mathrm{r}[\varepsilon ə]$

$\mathrm{a}+11$ [ว:] (wall) (divar)

$\mathrm{a}+1+$ consonant always

e + a [i:] (tea, meat) (çay, ət)

$\mathrm{e}+\mathrm{a}+\mathrm{r}$ [iə] (hear) (eşitmək)

$\mathrm{o}+\mathrm{a}$ [ou] (coat) (palto)

At the same time, conversion shows itself in two ways. On the one hand, under the influence of conversion, one sign (in this case "a") can denote different sounds (see examples above), on the other hand, the same sound can be indicated by different signs. For example:

[i:] [iə]

e ee ea er eer ear

(be) (meet) (tea) (here) (deer) (hear) (olmaq, görüşmək, çay, bura, maral, eşitmək)

Thus, in the English language, the sign /a/ is expressed in different sounds depending on the position in the word and on compatibility with other speech sounds. Some of these sounds under the influence of conversion begin to coincide with the sounds of other signs, which, in turn, under the influence of conversion, can also be indicated by other signs. Graphically, this can be described in the following way.

[ei] (gate) (darvaza)

A [i:] (tea) [ou] (no)

$\mathrm{E}[$ [ə] $\mathrm{O}$

(letter, doctor) (məktub, həkim)

As seen from the scheme, in the English language, sounds and letters are in constant interchangeability, that is, a sign denoting a certain sound in speech under the influence of conversion begins to expand its potential: either new sounds begin to be perceived under this sign, or a sound that is indicated by other signs. This relationship can be traced both at the linguistic and speech levels, and provides the English language with a limited number of letters and sounds to create new letter and sound combinations, and therefore new word-formation elements and words.

It is an interesting fact that conversion can transfer a unit of one language level into another. For example, the sound that is transmitted in the graphic system of the English language by a combination of the signs "a and r", at the wordformation level loses its priority position: the spelling "ar," which is perceived as a suffix, comes to the forefront, participating in the formation of new words, particularly, nouns: beggar, liar, scholar, etc.

At the word-formation level, the sign "a" can act as the prefix a-, which in the English language is polysemantic: a-1 /a/ prefix

1) in a particular condition or way: alive (= living)/ Read it aloud, please (= in a voice that others can hear);

2) literary or old-fashioned, used to show that someone or something is in or on something, or at a place: abed (= in bed) $\mid$ afar (= far away) | atop (= on top of something) a-2 /ei, æ/ prefix showing the opposite or the absence of something; not, without: atypically (= not typically) $\mid$ amoral (= not moral) (Longman 2001, p. 1).

The negative meaning of prefix a- forms new words, which related to the same part of speech, as an original. For example:

apolitical (Adj.) $\leftarrow$ political (Adj.) (siyasi)

amoral (Adj.) $\leftarrow$ moral (Adj.) (mənəvi)

awry (Adj.) $\leftarrow$ wry (Adj.) (əyilmiş) 
Adjectives formed in this way are one of the manifestations of the negation category in English. It means that coinciding in meaning with a negative particle "not", these prefixes can replace them in a sentence. The effect of conversion is that the negation in the English sentence can be expressed both with negative words or particles, and prefixes, which are syntactic synonyms in words: apolitical $=$ not political, amoral $=$ not moral.

In the meaning of finding a state or place the prefix a- forms a new word, which is related to the different part of speech, than original one:

1) Nouns are transferred to adjectives or adverbs: ablaze (Adj.) $\leftarrow$ blaze (N.); abed (Adj.) $\leftarrow$ bed (N.); afoot (Adj.) $\leftarrow$ foot $(\mathrm{N}$.);

2) Adjectives are transferred to adverbs: afar (Adv.) $\leftarrow$ far (Adj.); aloud (Adv.) $\leftarrow$ loud (Adj.); alow (Adv.) $\leftarrow$ low (Adj.).

In modern English, under the influence of conversion, the studied prefix has also begun to replace prepositions "off, from" and provide the words with sense of movement: akin, afresh, anew.

As mentioned before, conversion reveals the inner potential of linguistic units. However, concretization of the language mark may occur as a result of the conversion, that is, narrowing of either its meaning or the function it performs. This narrowing is also required by the law of the language saving principle.

\section{ANALYSES}

As already noted, conversion is an extension of the functional component of the sign. Under the influence of conversion, while maintaining its shape, a new sign can be transformed into:

A) a sign of another level of the English language system;

B) a sign of the same level of the English language system.

In the first case, conversion is heterogeneous signs, in the second, homogeneous signs. In turn, dissimilar signs serve to link the levels of the English language as a system, while homogeneous signs expand the potential of each level of the language. Moreover, both types of conversion are characterized by certain semantic transfers.

When forming conversion, three types of transfers are distinguished:

1) metaphorical;

2) homonymous;

3) transfer by function.

These three types of semantic transfer in English can be observed both in pure and mixed forms. Metaphorical transfer is based on the similarity of material characteristics: color, shape, character of movement. Relatedly, three types of metaphors are distinguished: motivated, synthetic and associative, which are observed during conversion.

1. Motivated linguistic metaphor: the semantic element explicitly links the metaphorical meaning with the original one. The metaphor in these cases is transparent. For example:

The police are looking for a man aged between 30 and 35. - My aged parents.

In both examples, "aged" is an adjective that differs functionally and semantically. In the first sentence, it acts as a participle II and is part of the participial construction, and also denotes a sign - indicates the age. In the second example, "aged" is a definition that conveys the semantics of the degree of the attribute - "very old" (parents). Consequently, under the influence of the conversion in the word "aged", an expansion of the syntactic function is observed, which entails the development of meaning, namely, a gradual meaning: a feature indicating age may also indicate the degree of this feature. In other words, conversion, thanks to a motivated metaphor, forms conversions-synonyms.

2. A syncretic linguistic metaphor based on sensations:

Aw shucks, you're making me blush! - He's filled with aw shucks niceness.

As an adjective, "aw shucks" means "shy". As an interjection, it also expresses this emotion. Consequently, a specific emotion by metaphorical transference becomes a sensual exclamation of embarrassment, timidity, and bashfulness. In this case, not only the shade of the meaning changes, but also the function. If "aw shucks" defines a noun as an adjective, then as an interjection this word becomes a direct, uncontrollable expression of emotion.

3. An associative linguistic metaphor is based on the ability of consciousness to find analogies between any objects of reality. Such a linguistic metaphor is based on the association of signs or psychological parallelism. For example:

an Afro-American - Afro (a hair style popular with African Americans)

In the first case, "Afro" is a prefix that denotes everything related to Africa, or people from Africa, and conveys the semantics of the feature. In the second case, "Afro" is a noun. Metaphorical transfer is observed here in the switching of a certain attribute to a specific concept. The transparency of the metaphor lies in the fact that the sign of people or things is transferred to the style, hairstyle that distinguishes these people in society. Therefore, in this case, we observe an associative metaphorical transfer based on a feature.

When converting between signs of the English language, cases of homonymous semantic transfer can also be observed. At the same time, the homonymy that arose under the influence of conversion differs from homonymy - a linguistic universal. Let's compare the two types of situations.

The heart of Indonesia, Java Islands, is an incredible destination to witness the complex Indonesian culture (www.traveltriangle.com, 10 March 2019). - Java is powering the innovation behind our digital world 
(www.oracle.com, 16 September 2019). - There has been a revolution in coffee making over the past decade, with one's choice and style of java becoming about as personalized as his or her fingerprints (Outdoor Life, 8 January 2020).

As you can see from the examples, in English, "Java" is the name of one of the Indonesian islands, the unofficial name of coffee and the programming language. According to the etymological dictionary, the unofficial name of coffee comes from the name of the island of Java: originally a kind of coffee grown on Java.

Consequently, two concepts - the name of the island and the designation of coffee - were formed on the basis of a motivated metaphor. In the twentieth century, namely in 1995, the unconventional name for coffee gave its name to the new software language Java.

However, despite the fact that etymologically all three words are interconnected, in modern English they are semantically different from each other, and, therefore, are homonyms.

In contrast to linguistic homonyms, homonyms that arise during conversion, despite their graphic coincidence, differ a) semantically, b) in part of speech, and, as a consequence, c) functionally. It is this homonymy that we observe, for example, in the word "acting".

In English, "acting" can be an adjective and a noun:

- The lack of acting (Adj.) Nominations could also spell doom for its chances (only 11 other films have ever won best picture without receiving nominations in any acting categories) (Washington Post, 3 February 2020).

- Tensions have grown between Hong Kong's ethnic minorities and protesters, who accuse South Asian gangs of acting $(N)$ as thugs for hire, paid by Triad criminal organizations and other shady groups to intimidates and beat up protesters (Time, 20 October 2019).

The sign "acting" was formed from the verb "act" by the suffixing method: "act + -ing". There is also a semantic difference. The noun "acting" has developed its meaning on the basis of functional transference, while the adjective "acting" on the basis of a motivated metaphor. At the same time, the meaning of a noun and an adjective is so different that in modern English they are perceived as homonyms.

Thus, the semantic component of conversion is three types of transfer of values: metaphorical, homonymous, and transfer by function. At the same time, the development of these meanings can be observed both in homogeneous units and heterogeneous ones, since all types of hyphenations we noted above are most often found in English in a mixed form.

\section{CONCLUSION}

Considering conversion from the point of view of cognitive linguistics in modern English provided the following results:

1. One of the principles of organization and existence of language is the principle of economy, when the language strives to achieve the greatest result using fewer means. This phenomenon is possible due to the asymmetric dualism of the sign.

Conversion in this case is a mechanism that incorporates the new into the old framework and qualitatively changes the internal content of the sign. In this case, the conversion:

1) associates a sign with an object;

2) connects the sign with other signs;

3) combines the signs as the means of reflecting thoughts.

In other words, conversion as a mechanism of the principle of linguistic economy under one form unites different semantic concepts, and also transfers linguistic units of one level to another.

2. Depending on the mode of action, the conversion is built according to certain structural models that characterize the most significant connections and conversion properties. These connections and properties are revealed as a result of the functioning of the components of the conversion model.

3. In modern English, conversion operates at all linguistic levels: phonetic, derivational, morphological, lexical and syntactic. It expands the potential capabilities not only of units of the same language level (i.e., it is homogeneous), but also of units of different levels of the language (i.e., it is heterogeneous). In other words, conversion is an extension of the functional component of the sign.

4. In modern English, the cases of conversion actions are associated with the development of certain categories, for example: the category of negation, the category of quantity, the category of self, the category of gender, etc.

5. Conversion is based on 3 types of semantic hyphenation:

1) metaphorical;

2) homonymous;

3) transfer by function.

Arising on the basis of these semantic transfers, the conversion serves the development between conversions of such universal phenomena of language as polysemy, homonymy, synonymy and antonymy.

\section{REFERENCES}

[1] Babanl1, G. (2017). Semantic analysis of the term conversion // Terminology issues. Baku: Mutarjim, № 2. 
[2] Bauer, L. (2002). English word-formation. Cambridge: Cambridge University Press.

[3] Bloomfield, L. (1948). Language. New York: Henry Holt and Company.

[4] Bloomfielf, M.W. (1965). A Linguistic Introduction to the History of English. USA: New York Publishing House.

[5] Hadjiyeva, Ch. (2015). The role and importance of neologisms in the development of conversion phenomena and techniques in linguistics // Philological issues. Baku: Science and education, № 10.

[6] Huseynova, R.H. (2017). New word creation in English by conversion and its methods of expression in Azerbaijani // Philological issues. Baku: Science and Education, № 1.

[7] Kaptsevskiy, S.O. (1965). On asymmetric dualism of a linguistic sign // Zveqintsev, V.A. History of linguistics of the XIX-XX centuries in sketches and extracts. Moscow: Science and Education Publishing House.

[8] Kubryakova, E.S. (1991). Lexicon and modern problems of its study // Picture of the world: lexicon and text (based on the English language): Selection scientific volum: MSLU, M.: MSLU Publishing House.

[9] Lakoff, G. (1988). Cognitive semantics // Meaning and mental representation. Ed. by Umberto Eco, Marco Santambrogio, Patrizia Violi, Bloomington and Indianapolis: New Press Publishing House.

[10] Lakoff, G., Johnson, M. (2003). Metaphors we live by. Chicago: The Chicago University Press.

[11] Longman. (2001). Advanced American Dictionary. England: Edinburg Publishing House.

[12] Mammadov, A., Mammadov M. (2010). Cognitive perspectives of discourse analysis. Baku: Chashioglu Publishing House.

[13] Mammadov, T.M. (2006). About conversion // Baku University News, Humanities Series. Baku: Mutarjim, 2006, № 2.

[14] Nasirova, R.M. (2017). Typology of morphological methods in different system languages: / the abstract of the scientific dissertation of the doctor of philosophy on philology / Baku: Philological Sciences, 2017.

[15] Orudjeva, S.A. (2016). Language conversion event: / the abstract of the doctoral dissertation on philology / Baku: Baku Publishing House, 2016.

[16] Smirnitsky, A.I. (1954). About the conversion to English // Foreign languages at school. № 3, Moscow: Moscow Publishing House.

[17] Veysalli, F.Y. (2015). Cognitive linguistics: basic concepts and perspectives. Studia Philologica VII. Baku: Mutarjim.

Laila Sahib Gadimova was born in 1980 in Baku, Azerbaijan. She graduated from the Baku Slavic University in 2001, and she got her Master Degree of Region Studies. She had some training and courses such as Regional Centre of the International Educational programs (2001-2002), Durham Technical Community College (USA, Durham NC) (2004-2005), etc.

She has been teaching at the Azerbaijan University of Languages from 2013 till present. She speaks English and Russian fluently. 